ISSN 2413-0877 Volume 3 (2016) 138-141

ICoA Conference Proceedings, 7 - 9 November 2015

\title{
Determination of Transportation Fleet Size using The Combination of Adjusted SPT Rule and Linear Programming Method
}

\author{
Pujo Saroyo ${ }^{* 1}$ and M.P.A Wibowo \\ ${ }^{1}$ Department of Agro-industrial Technology, Faculty of Agricultural Technology \\ Universitas Gadjah Mada, Jl. Flora No.1 Bulaksumur 55281, Indonesia. \\ Email: pujosaroyo@gmail.com*
}

\begin{abstract}
In a very competitive industry, XYZ Ltd. needs to have an effective, efficient and reliable logistics fleet management. The fleets should be able to help the company serve the market demands and guarantee the distribution of its products. This research analyzed and determined the by-truck transportation fleet size of XYZ Ltd using the combination of adjusted SPT Rule and linear programming method. The results showed that the product delivery's scheduling was arranged by operating a fleet of 13 tronton trucks and 25 trailer trucks, with the scheduling of delivery resulting in maximum makespan of 6.98 days and an average flow-time per shipment of 3.83 days.
\end{abstract}

Keywords: Fleet Management, Logistics Transportation, Adjusted SPT

\section{INTRODUCTION}

As a company engaged in industrial competition, XYZ Ltd. needs to manage its logistics fleets effectively, efficiently and reliably. Its fleets should be able to support the company in fulfilling demand for its products so that its supply remains available in the market. When distributing its logistics, XYZ Ltd. does not have its own transportation fleets. Instead, the company uses train services (less than $40 \%$ ) and truck transportation services (more than $60 \%$ ) provided by a third party logistics under the agreement /contract. At the moment, logistics distribution by train has been deemed to give less satisfying services when it is compared to those by truck in terms of on time delivery and product damage (Saroyo et al, 2009).

The use of transportation fleets managed by third party is one of methods to improve the efficiency of logistics distribution. However, giving full authority to third party logistics to manage logistics distribution can result in the lack of transportation fleets when the demand for its products is very high. As a consequence, delays in products delivery cannot be avoided.

In order to improve the company's logistics distribution management, strategic steps need to be undertaken. This study determined transportation fleet size using the combination of adjusted SPT rule and linear programming method, by considering its best scheduling arrangement.

\section{RESEARCH METHODOLOGY}

\subsection{Literature review}

Linear programming has been used to solve optimization problems in industries, such as transportation problems, job scheduling and others (Chung C, 2004; Anderson et al. 2000). Job scheduling are usually applied in solving problems of machine scheduling (Said et al, 2015; Jinwei et al, 2014). Nevertheless, based on similar characteristics of problems, job scheduling can also be applied in transportation scheduling including the determination of its fleet size.

In general, scheduling methods are heuristic methods that assign the commencement and completion of a series of tasks in accordance with the expected goals. Some of considerable criteria of scheduling problem would be average flowtime and makespan minimization (Pasupuleti, 2012). Makespan minimization indicates that planners want the results of scheduling jobs with the fastest completion time of all work to be done, while the average minimization flowtime emphasis more on reducing the time lost as a result of waiting too long to complete the job.

Job Scheduling can be done with the approaches of Shortest Processing Time (SPT) to prioritize the scheduling of the job with the fastest time, Longest Processing Time (LPT) which prioritizes the scheduling of the job with 
the longest time, First Come First Serve (FCFS) which prioritize work coming early, and Last Come First Serve (LCFS) which prioritize work coming last (Elsayed, 1994; Baharom et al., 2014). In some cases, SPT method has several advantages. For the completion of work on a single processing unit or equipment, SPT method is capable of minimizing the average flow time and average time delay or lateness and tardiness (Sharma and Jain, 2014). For completing the jobs by means of parallel processing unit or equipment, SPT method is able to ensure the minimization of the average flow time of all completed jobs.

\subsection{Method of Analysis}

The determination of transportation fleet size was carried out on the basis for fulfiling the requirements in the forthcoming years. Therefore, the sales growth rate of company's product per year will be used as a basis for predicting the demand in the future. Similarly, the inflation rate per year was used as the basis for estimating the costs of transport in the next few years. The steps used to determine the needs of the transportation fleet are as follows:

1. The determination of transportation fleet size for respective destination was conducted using linear programming methods with the general formula:

Min Z = C_tronton X_tronton + C_trailer

$$
\text { X_trailer }
$$

Constraints:

K_tronton X_tronton + K_trailer X_trailer =

D, X_tronton, X_trailer $>=0$

Where:

Min $\mathrm{Z}=$ minimization of delivery costs

C_tronton $=$ cost of transport per shipment using a fleet of tronton trucks

C_trailer $=$ cost of transport per shipment using a fleet of trailer trucks

X_tronton $=$ frequency of delivery to the destination location with a fleet of tronton trucks

$\mathrm{X}$-trailer $=$ frequency of delivery to the destination location with a fleet of trailer trucks

K_tronton = capacity of a tronton truck (20 tons)

K_trailer = capacity of a trailer truck (37.5 tons)

$\mathrm{D}$ = Estimated demand for the company's product in 2013 to the intended location.

The scheduling procedure was carried out using "Adjusted SPT Rule" method by giving priority on the fulfilment of demand at respective destination, taking into account the delivery time $\left(p_{j}\right)$, the readiness for departure $\left(r_{j}\right)$, the completion time of delivery $\left(\mathrm{C}_{\mathrm{j}}\right)$, the submission deadline $\left(\mathrm{d}_{\mathrm{j}}\right)$, the time span between a truck was ready to depart until the its return to the factory (delivery time plus wating time for shipment) or flowtime $\left(F_{j}\right)$ and the longest time completing all tasks or makespan $\left(\mathrm{M}_{\mathrm{j}}\right)$. Flow time and makespan is calculated by:

$$
\begin{aligned}
& \text { Flow time, } F_{j}=C_{j}-r_{j}\left(F_{j}>0\right) \\
& \text { Makespan, } M_{j}=C_{\max }=\max \left\{C_{j}\right.
\end{aligned}
$$

2. Steps for scheduling using "Adjusted SPT Rule" method:

a. Determine the number of trucks that will be used as the transportation unit

b. Sort the delivery time $\left(\mathrm{p}_{\mathrm{j}}\right)$ to each destination by the shortest time (Short Processing Time or SPT rule). Delivery time $\left(\mathrm{p}_{\mathrm{j}}\right)$ to the same destination location is not considered anymore

c. In the delivery stage I, allocate the first truck for delivery to the destination having shortest delivery time $\left(\mathrm{p}_{\mathrm{j}}\right)$.

$\mathrm{d}$. Allocate the next truck for delivery to the different destination having the next shortest delivery time $\left(\mathrm{p}_{\mathrm{j}}\right)$. Repeat this step until the delivery to the different destination with the longest delivery time $\left(p_{j}\right)$ has been scheduled. If so but all trucks have yet to be assigned then follow step e. If so and all trucks have been assigned then follow step $\mathrm{f}$.

e. Allocate the next truck for delivery to the destination having the shortest delivery time $\left(\mathrm{p}_{\mathrm{j}}\right)$ again. Go back to stage $\mathrm{d}$.

$f$. For the next delivery stage, allocate delivery by truck again to the destination having delivery time $\left(\mathrm{p}_{\mathrm{j}}\right)$ which is slightly longer than the last delivery time during to the previous delivery stage, with the shortest completion time of delivery $\left(\mathrm{C}_{\mathrm{j}}\right)$. If the last delivery time of the last delivery stage is the longest delivery time $\left(\mathrm{p}_{\mathrm{j}}\right)$ then allocate the delivery by truck to the destination having the shortest delivery time $\left(\mathrm{p}_{\mathrm{j}}\right)$ and the shortest completion time of delivery $\left(C_{j}\right)$ again. Do the allocation of delivery for all the available fleet of trucks.

g. Repeat step $f$ until all of the needs of product delivery to the destination has been fulfilled.

h. Identify the truck with its make span $\left(\mathrm{C}_{\max }\right)$ greater than the delivery time limit $\left.\left(\mathrm{d}_{\mathrm{j}}\right)\right)$. If not available then follow the step i. But if 
so, then move all shipments that exceed the deadline to the additional trucks that should be provided with procedures following step no. a to $\mathrm{h}$.

i. Scheduling is completed.

The fleet of trucks used for delivery of the product were tronton trucks with the capacity of 20 tons and trailers with the capacity of 37.5 tons. XYZ Ltd. delivered its products to its warehouses located in Lempuyangan station, Purwosari and Balapan station, Sragen stations as well as stations at Brumbung and Poncol.

\section{RESULTS AND DISCUSSION}

Based on the annual report, sales of its product increased by $11 \%$ from the previous year. Therefore, the determination of transportation fleet size was based on its demand increase of $11 \%$ per year over the next 5 years. The costs of product deliveries by trucks were not the same among the stations. This resulted from different distances of shipments and different number of products delivered. This research assumed the cost inflation of $10 \%$ per year.

In order to determine the transportation fleet size required to deliver company's products on the scheduled time then the approximation of distance and delivery time to the intended six stations had to be known. Based on a survey, the speeds of trucks for delivery to the destination stations were very slow, with the maximum speed of $60 \mathrm{~km} / \mathrm{h}$ or an average of $30 \mathrm{~km} / \mathrm{h}$. Whereas on the return trip back to the factory, the trucks could run faster with a maximum speed of $75 \mathrm{~km} / \mathrm{h}$ or an average of $37.5 \mathrm{~km} / \mathrm{h}$.

In order to find the best combination of transportation fleet, the total cost approaches of all shipments using either a tronton truck or a trailer truck were applied by considering its capacity. The formula used were adopted from formula (1) and (2) above. For example, for delivery to the Poncol station totaling 854.9 tons of products, the cost of shipment by tronton truck was IDR.168,202,- per ton. Therefore, the cost per shipment of 20 tons or C_tronton would be equal to (IDR.168,202,per ton $\times 20$ ton) or IDR.3,364,040,-. In the same way, the shipment of 37.5 tons of products by trailer truck or C_trailer was (IDR.168,202,- per ton $\mathrm{x} 37.5$ tons) or IDR.6,307,575,-- $\quad$ Thus, optimization formulation for Poncol delivery would be:

Min $Z=3,364,040$ X_tronton $+6,307,575$ X_trailer

Constraints:

20 X_trailer +37.5 X_tronton $=854.9$, X_tronton, X_trailer $>=0$

When the formulation was solved then we would get the results that $X$ _tronton $=9$ times and $\mathrm{X}$ _trailer $=18$ times. For fulfilling the deadline, the results of scheduling using Adjusted Shortest Processing Time (SPT) rule recommended the use of 13 units of tronton trucks 25 units of trailer trailer. Delivery using tronton trucks took maximum makespan of 6.42 days, with the average flow time per shipment of 3.59 days and allocating 3 dedicated tronton trucks for delivery to Sragen station (see Fig.1). On the other hand, scheduling with a fleet of trailer truck took maximum makespan of 6.98 days, with the average flow time per shipment of 3.83 days and allocating 1 dedicated trailer truck for delivery to the Lempuyangan station (see Fig. 2).

\begin{tabular}{|c|c|c|c|c|c|c|c|}
\hline \multirow{2}{*}{ TRONTON } & \multicolumn{7}{|c|}{ ith Delivery } \\
\hline & $T$ & II & III & IV & V & VI & VII \\
\hline Tronton 1 & 20,22 & 22,02 & 22,02 & 22,02 & 22,02 & 22,02 & 22,02 \\
\hline Tronton 2 & 22,02 & 22,02 & 22,02 & 22,02 & 22,02 & 22,02 & 22,02 \\
\hline Tronton 3 & 22,03 & 22,02 & 22,02 & 22,02 & 22,02 & 22,02 & 22,02 \\
\hline Tronton 4 & 20,22 & 22,03 & 22,02 & 22,02 & 22,02 & 22,02 & 22,02 \\
\hline Tronton 5 & 22,02 & 22,03 & 22,02 & 22,02 & 22,02 & 22,02 & 22,02 \\
\hline Tronton 6 & 22,03 & 22,03 & 22,02 & 22,02 & 22,02 & 22,02 & 22,02 \\
\hline Tronton 7 & 20,22 & 22,02 & 22,02 & 22,02 & 22,02 & 22,02 & 22,02 \\
\hline Tronton 8 & 22,02 & 22,02 & 22,02 & 22,02 & 22,02 & 22,02 & 22,02 \\
\hline Tronton 9 & 22,03 & 22,02 & 22,02 & 22,02 & 22,02 & 22,02 & 22,02 \\
\hline Tronton 10 & 20,22 & 22,03 & 22,02 & 22,02 & 22,02 & 22,02 & 22,02 \\
\hline Tronton 11 & 22,02 & 22,03 & 22,02 & 22,02 & 22,02 & 22,02 & 22,02 \\
\hline Tronton 12 & $\overline{22,03}$ & 22,02 & 22,02 & 22,02 & 22,02 & 22,02 & 22,02 \\
\hline Tronton 13 & 22,02 & 22,02 & ND & ND & ND & ND & ND \\
\hline
\end{tabular}

Figure 1. Result of delivery scheduling using tronton (combination method) 


\begin{tabular}{|c|c|c|c|c|c|c|c|c|c|}
\hline \multirow{2}{*}{ TRAILER } & \multicolumn{9}{|c|}{$i^{\text {nn }}$ Delivery } \\
\hline & $\mathrm{I}$ & II & III & IV & $\mathrm{V}$ & VI & VII & VIII & IX \\
\hline Trailer 1 & 15,26 & 22,03 & 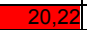 & 22,03 & 20,04 & 22,03 & 22,03 & 15,26 & ND \\
\hline Trailer 2 & 20,04 & 22,03 & 20,04 & 22,03 & 22,03 & 20,22 & 15,26 & 15,26 & ND \\
\hline Trailer 3 & 20,22 & 22,03 & 15,26 & 15,26 & 15,26 & 20,04 & 15,26 & 15,26 & 15,26 \\
\hline Trailer 4 & 22,03 & 22,03 & 22,03 & 22,03 & 15,26 & 15,26 & 15,26 & 15,26 & 15,26 \\
\hline Trailer 5 & 22,03 & 15,26 & 22,03 & 20,04 & 20,22 & 15,26 & 15,26 & 15,26 & 15,26 \\
\hline Trailer 6 & 15,26 & 15,26 & 20,22 & 20,04 & 20,04 & 20,22 & 15,26 & 15,26 & 15,26 \\
\hline Trailer 7 & 20,04 & 15,26 & 22,03 & 20,04 & 20,22 & 20,22 & 22,03 & 15,26 & ND \\
\hline Trailer 8 & 20,22 & 15,26 & 15,26 & 20,22 & 20,22 & 22,03 & 15,26 & 15,26 & 15,26 \\
\hline Trailer 9 & 22,03 & 20,04 & 20,22 & 15,26 & 22,03 & 20,22 & 22,03 & 15,26 & ND \\
\hline Trailer 10 & 22,03 & 22,03 & 22,03 & 15,26 & 22,03 & 20,22 & 15,26 & 15,26 & ND \\
\hline Trailer 11 & 15,26 & 20,04 & 22,03 & 20,22 & 15,26 & 15,26 & 20,22 & 15,26 & 15,26 \\
\hline Trailer 12 & 20,04 & 20,04 & 20,22 & 22,03 & 15,26 & 22,03 & 22,03 & 15,26 & $\mathrm{ND}$ \\
\hline Trailer 13 & 20,22 & 20,04 & 22,03 & 20,04 & 20,04 & 20,22 & 22,03 & 15,26 & ND \\
\hline Trailer 14 & 22,03 & 20,04 & 22,03 & 15,26 & 22,03 & 15,26 & 22,03 & 15,26 & ND \\
\hline Trailer 15 & 22,03 & 15,26 & 15,26 & 22,03 & 20,04 & 22,03 & 15,26 & 15,26 & 15,26 \\
\hline Trailer 16 & 15,26 & 20,22 & 20,04 & 22,03 & 20,04 & 15,26 & 22,03 & 15,26 & 15,26 \\
\hline Trailer 17 & 20,04 & 20,22 & 22,03 & 20,22 & 20,22 & 22,03 & 22,03 & 15,26 & ND \\
\hline Trailer 18 & 20,22 & 20,22 & 15,26 & 15,26 & 22,03 & 20,22 & 22,03 & 15,26 & 15,26 \\
\hline Trailer 19 & 22,03 & 20,22 & 20,04 & 22,03 & 20,04 & 22,03 & 22,03 & 15,26 & $\mathrm{ND}$ \\
\hline Trailer 20 & 22,03 & 20,04 & 22,03 & 20,04 & 15,26 & 20,22 & 15,26 & 15,26 & 15,26 \\
\hline Trailer 21 & 15,26 & 22,03 & 20,04 & 22,03 & 15,26 & 15,26 & 22,03 & 15,26 & 15,26 \\
\hline Trailer 22 & 20,04 & 22,03 & 22,03 & 20,22 & 20,22 & 15,26 & 15,26 & 15,26 & 15,26 \\
\hline Trailer 23 & 20,22 & 22,03 & 20,22 & 22,03 & 22,03 & 22,03 & 15,26 & 15,26 & $\mathrm{ND}$ \\
\hline Trailer 24 & 22,03 & 22,03 & 15,26 & 20,22 & 20,22 & 22,03 & 15,26 & 15,26 & 15,26 \\
\hline Trailer 25 & 15,26 & 15,26 & 15,26 & 15,26 & 15,26 & 15,26 & 15,26 & 15,26 & 15,26 \\
\hline
\end{tabular}

Figure 2. Result of delivery scheduling using trailer (combination method)

\section{CONCLUSIONS}

The best delivery scheduling using combination of adjusted SPT rule and linear programming method recommended the use of 13 tronton trucks and 25 trailers trucks with the details of scheduling:

1. Scheduling with a fleet of tronton trucks:

a. The maximum makespan was 6.42 days.

b. The average flow time per shipment was 3.59 days

c. Allocate 3 dedicated tronton trucks for delivery to Sragen station.

2. Scheduling with a fleet of Trailer trucks:

a. The maximum makespan was 6.98 days.

b. The average flow time per shipment was 3.83 days

c. Allocate 1 dedicated trailer trucks for delivery to Lempuyangan station.

\section{REFERENCES}

Anderson, D.R., Sweeney D.J.,Williams T.A.,(2000), An Introduction to Management Science, Quantitative Approaches to Decision Making, South Western College Publishing.

Baharom M.Z, Nazdah W, and Hussin W. 2014. Scheduling Analysis for Job Sequencing in Veneer Lamination Line. Journal of Industrial and Intelligent Information Vol. 3, No. 3, September 2015. Malaysia

Chung C., (2004), Simulation Modeling Handbook: A practical Approach, CRC Press.

Christopher, M., (2006), Logistics and Supply Chain Management, Financial Times Prentice Hall.
Elsayed, Elsayed, (1994), Analysis and control of Production Systems, Englewood Cliffs, 2nd Edition, Prentice Hall, London

Jinwei G, Manzhan G and Xingsheng G, 2014. Optimal Rules for Single Machine Scheduling with Stochastic Breakdowns. Research Article. Hindawi Publishing CoIDRoration Mathematical Problems in Engineering Volume 2014,

Pasupuleti, V.C., 2012. Scheduling in Cellular Manufacturing. Systemsiberoamerican Journal of Industrial Engineering, Florianópolis, SC, Brasil, v. 4, n. 7, p. 231243.

Runhaar, H. A C, (2002), Freight transport: at any price?, Effect of Transport on Book and Newspaper Supply Chains in the Netherlands, Delft University, Dutch.

Said N., Mouelhi W, and Ghedira K 2015. Classification Rules for the Job Shop Scheduling Problem with Machine Breakdowns. International Journal of Information and Electronics Engineering, Vol. 5, No. 4, July.

Saroyo P, Riyadi I.P and Gunawan H.E, 2009. Warehouse Capacity Optimization at Railway Station, National Excellent Research (Rusnas) UGM 2009, Universitas Gadjah Mada, Yogyakarta

Sharma, P and Jain A 2014. Scheduling $a$ Stochastic Dynamic Job Shop Manufacturing System with Sequencedependent Setup Times. 5th International \& 26th All India Manufacturing Technology, Design and Research Conference December 12th-14th 